\title{
The Influence of Corrosion on Mechanical Properties of Nigerian Mild Steel
}

\author{
Usikpedo Charles Olordo \& Asibeluo Imonifewo Stephen \\ Department Of Mechaical Engineering \\ School Of Engineering \\ Delta State Polytechnic \\ Ogwashi-Uku \\ Delta State
}

\begin{abstract}
This research entails subjecting a number of specimens to various environmental medium such as air, rain water, acidic water and salty water. The acidic water was prepared by adding water to concentrated tetraoxosulphate vi acid $\left(\mathrm{H}_{2} \mathrm{SO}_{4}\right)$, while the salty water was prepared by adding common salt (Sodium Chloride, $\mathrm{NaCl}$ ) to water. The specimens labeled $\mathrm{A}$ $D$ were prepared by welding while specimens $E-H$ were produced by machining. Specimens A-D were subjected to Brinnell hardness test while specimens E-H were subjected to Brinnell hardness test and impact toughness test. Lastly, the data gathered were subjected to either Analysis of Variance Test (ANOVA) or Chi-square tests.
\end{abstract}

Keywords: Influence, Corrosion, Mechanical Properties, Nigerian Mild Steel

Aims Research Journal Refaranca Fnmat:

Usikpedo Charles Olordo \& Asibeluo Imonifewo Stephen (2018): The Influence of Corrosion on Mechanical Properties of Nigerian Mild Steel. Advances in Multidisciplinary \&. Scientific Research Journal. Vol. 4. No.1, Pp43-50

\section{INTRODUCTION}

According to Emeghara and Iroanya (1999), corrosion is the deterioration or degradation of the properties of material by virtue of the interaction between the material and environment. Corrosion of a material can be engendered by chemical reaction with the environment, mechanical interaction or a combination of the two. To one degree or another, most material experience some type of interaction with a large number of diverse environments. Often, such interaction impair a material's usefulness as a result of the deterioration of its mechanical properties (e.g durability and strength), and other physical properties or appearances. In metals, there is actual material loss either by dissolution (corrosion) or by the formation of non-metallic scale or film (oxidation). Callister (2011).

According to Idenyi, Neife and Uzor (2004), most metals occur in nature in the combined state as ores. After extraction and processing of the ores to metals, they become unstable as they are left in the uncombined form. Throughout the service life therefore, they strive to revert to their natural combined state. Borode and Okpala (1999). Several factors are known to accelerate the corrosion of metal and alloys. Such factors include the composition of the metals and alloys and their surface finish to mention just a few. Conditions in which metals operate are many and varied. They range from highly acidic to highly caustic solution, underground and above to highly caustic aqueous solutions, underground and above ground, arid to very wet and from cryogenic to incandescent temperatures. Nwoko and Umoru (1998). According to Ihom (2004); corrosion can be a very serious problem when it occurs unexpectedly and emergency measures have to be taken to deal with it. The effects of corrosion have resulted to a lot of waste and destruction of materials and equipment in both industrialized and developing Nations. The problems of automobiles parts corrosion, oil pipeline corrosion, and industrial parts corrosion in Nigeria cannot be over emphasized.

There is need to find the causes and effects of corrosion so that appropriate measures can be recommended to curb it or reduce it to the barest minımum.

\subsection{Problem Statément}

Many Nigerian infrastructures such as bridges, industrial machines, automobile vehicles and oil pipelines are plagued by the malady of corrosion. This has resulted in some of them being partially functional while others are completely broken down. There is need to make a study on the causes and effects of corrosion so that these problems can be adequately addressed. 


\author{
1.2 Aims And Objective Of The Study \\ The aims and objective of this research are as follows: \\ 1. To determine the effect of corrosion on mechanical properties of mild steal \\ 2. To determine the effect of certain medium like air, rain water, salty water and acidic water on the rate of corrosion. \\ 3. To find the causes of corrosion \\ 4. To make adequate recommendation to minimize corrosion and prevent it completely.
}

\title{
1.3 Significance of Study
}

This research work is of paramount importance because of the huge cost of corroded structures in this country. The high amount spent on the maintenance and reconditioning of these structures cannot be over-emphasized.

The choice of mild steel is significant because most engineering components are made of mild steel. According to Chakravarthy and Mohana (2013); mild steel is the most important engineering material particularly for structural, instrumental, industrial and automobile application. Corrosion problem occurs in these industries and can cause disastrous damage to metal and alloy structures causing economic consequences in terms of repair, replacement and products losses.

Steel plays a very important role in national industrialization processes. This is because steel remains the basic material for a hosts of manufacturing activities and hence the material backbone for national economic development and growth generally. Okonji and Ikpesini (2008). Welded joint was considered as parts of the project due to the fact that most of the components of machines and infrastructures are usually welded.

According to Renato etal (2014); accelerated tests such as salt spray are of major interest for a variety of industries due to their ability of providing results more quickly than those obtained from natural weathering; giving support to the development of new alloys and protective coating

\subsection{Scope and Limitation}

The scope of this research entails preparation of four specimens by the welding of mild steel plates using mild steel electrode, machining of other four specimens and subjecting them to medium such as air, rain water, salty water and acidic water. It also entails carrying out material testing on the various specimens after being treated with the four media for a period of three months. The research is limited to the availability of mild steel plates and bars and welding rods whose composition depends on what is available in the Nigerian market. It is also limited to the availability of testing equipment that is the use of analog equipment instead of digital in some cases.

\section{RESEARCH DESIGN}

This research encompasses physical tests and mechanical tests. The physical tests entail physical observation of colour of specimens, measurement of weight using chemical digital balance and measurement of weight loss. The rate of corrosion in mil per year was also determined. The mechanical tests involve hardness and toughness tests of the specimens. The hardness tests were carried out using the Brinnell hardness testing machine, while the toughness tests were carried out using Charpy Testing

\subsection{Samples Preparation}

The samples for these tests were labeled from letter $A-H$. Samples $A-D$ were prepared by measuring and marking out a length of about $60 \mathrm{~mm}$ from a mild steel flat bar of length $1000 \mathrm{~mm}$, width $24 \mathrm{~mm}$ and height $4 \mathrm{~mm}$ and cutting them to size using the disc and bobbling sander (Hand Cutting Machine). These samples were finally welded using the arc welding machine. The gauge of electrode used for this purpose was gauge 12. Samples $E-H$ were produced by marking out a length of about $60 \mathrm{~mm}$ from a mild steel rod of diameter $12 \mathrm{~mm}$. These sambles were machined to cuboid shape with dimensions of length $55 \mathrm{~mm}$, breadth $10 \mathrm{~mm}$ and height $10 \mathrm{~mm}$. A vee-notched was formed on each specimen using shaping machine. It should be noted that samples $A$ and $E$ were controlled while the others were treated with chemical before testing.

\subsection{Rate Of Corrosion}

The rate of corrosion can be expressed on a variety of ways such as percentage weight loss; milligrams per square centimeter per day, and grams per square centimeter per day, and grams per square inch per hour. These do not express corrosion resistance in terms of penetration. From an engineering view point, the rate of penetration, or the thinning of structural piece can be used to predict the life of a given component. Fontana (2007). The expression mil per year is the most desirable way of expressing corrosion rates and will be used in this research. 
This expression is readily calculated from the weight loss of the metal specimen during the corrosion test by the formula given below;

$$
\text { Mpy }=\frac{534 \mathrm{w}}{\mathrm{DAT}}
$$

Where

$W=$ Weight loss, $\mathrm{mg}$

$D=$ Density of specimen $-\mathrm{g} / \mathrm{cm} 3$.

A = Area of specimen, sn in

$\mathrm{T}=$ Exposure time, hour.

\section{RESULTS OF PHYSICAL TESTS}

The results of physical are displayed in table 4.1. It consists of measurement of weights at specific time interval of one week (168hrs) calculation of weight loss and surface area of specimens, and eventual calculation of mils per year

TABLE 4.1: Measurement of Weight Loss and Calculation of mpy

\begin{tabular}{|c|c|c|c|c|c|c|c|c|c|c|c|c|c|c|c|c|c|}
\hline Specimen & Medium & $\begin{array}{l}\text { Initialweil } \\
\text { ght } \\
\text { HRS }\end{array}$ & $\begin{array}{l}1^{\prime \prime} \mathrm{wk} \\
168 \mathrm{hrs}\end{array}$ & $\begin{array}{l}2^{\text {nd }} \mathrm{wk} \\
336 \mathrm{hrs}\end{array}$ & $\begin{array}{l}3^{\prime \prime \prime} \text { wh } \\
\text { 504hrs }\end{array}$ & $\begin{array}{l}4^{\prime \prime} \mathrm{wk} \\
672 \mathrm{hrs}\end{array}$ & $\begin{array}{l}5^{501} \mathrm{wk} \\
840 \mathrm{hrs}\end{array}$ & $\begin{array}{c}6^{61} \mathrm{wk} \\
1008 \mathrm{hrs}\end{array}$ & $\begin{array}{c}7^{\text {"n }} \mathrm{wk} \\
1176 \mathrm{hrs}\end{array}$ & $\begin{array}{c}8^{87} \mathrm{wk} \\
1344 \mathrm{hrs}\end{array}$ & $\begin{array}{c}9^{\prime \prime \prime} \mathrm{wk} \\
1512 \mathrm{hrs}\end{array}$ & $\begin{array}{l}10^{10 "} \mathrm{wk} \\
1680 \mathrm{hrs}\end{array}$ & $\begin{array}{l}11^{\prime \prime \prime ~ w k ~} \\
1846 \mathrm{hrs}\end{array}$ & $\begin{array}{l}12^{m "} \mathrm{wk} \\
2016 \mathrm{hrs}\end{array}$ & $\begin{array}{l}\text { WK } \\
\text { Loss }\end{array}$ & $\begin{array}{c}\text { Area } \\
\text { Sq- } \\
\text { in }\end{array}$ & mpy \\
\hline A & Air & $0.866 \mathrm{~N}$ & $0.866 \mathrm{~N}$ & $0.866 \mathrm{~N}$ & $0.866 \mathrm{~N}$ & $0.866 \mathrm{~N}$ & $0.866 \mathrm{~N}$ & $0.866 \mathrm{~N}$ & $0.865 \mathrm{~N}$ & $0.865 \mathrm{~N}$ & $0.865 \mathrm{~N}$ & $0.863 \mathrm{~N}$ & $0.865 \mathrm{~N}$ & $0.863 \mathrm{~N}$ & $0.003 \mathrm{~N}$ & 10.26 & $\begin{array}{l}9.87 \\
\times 10^{4} \\
\end{array}$ \\
\hline $\bar{B}$ & $\begin{array}{l}\text { Rain } \\
\text { water }\end{array}$ & $0.858 \mathrm{~N}$ & $0.858 \mathrm{~N}$ & $0.858 \mathrm{~N}$ & $0.858 \mathrm{~N}$ & $0.858 \mathrm{~N}$ & $0.858 \mathrm{~N}$ & $0.858 \mathrm{~N}$ & $0.857 \mathrm{~N}$ & $0.857 \mathrm{~N}$ & $0.857 \mathrm{~N}$ & $0.856 \mathrm{~N}$ & $0.856 \mathrm{~N}$ & $0.856 \mathrm{~N}$ & $0.002 \mathrm{~N}$ & 10.26 & $\begin{array}{l}6.58 x \\
10^{4} \\
\end{array}$ \\
\hline c & $\begin{array}{l}\text { Acidic } \\
\text { water }\end{array}$ & $0.822 \mathrm{~N}$ & $0.822 \mathrm{~N}$ & $0.822 \mathrm{~N}$ & $0.821 \mathrm{~N}$ & $0.821 \mathrm{~N}$ & $0.820 \mathrm{~N}$ & $0.819 \mathrm{~N}$ & $0.818 \mathrm{~N}$ & $0.817 \mathrm{~N}$ & $0.815 \mathrm{~N}$ & $0.813 \mathrm{~N}$ & $0.799 \mathrm{~N}$ & $0.787 \mathrm{~N}$ & $0.005 \mathrm{~N}$ & 9.62 & $\begin{array}{r}1.75 \\
\times 10^{4}\end{array}$ \\
\hline D & $\begin{array}{l}\text { Saity } \\
\text { water }\end{array}$ & $0.852 \mathrm{~N}$ & $0.852 \mathrm{~N}$ & $0.850 \mathrm{~N}$ & $0.850 \mathrm{~N}$ & $0.850 \mathrm{~N}$ & $0.849 \mathrm{~N}$ & $0.849 \mathrm{~N}$ & $0.847 \mathrm{~N}$ & $0.843 \mathrm{~N}$ & $0.835 \mathrm{~N}$ & $0.826 \mathrm{~N}$ & $0.819 \mathrm{~N}$ & $0.806 \mathrm{~N}$ & $0.048 \mathrm{~N}$ & 9.78 & $\begin{array}{l}1.66 \\
\times 10^{-4} \\
\end{array}$ \\
\hline$E$ & Air & $0.422 \mathrm{~N}$ & $0.422 \mathrm{~N}$ & $0.422 \mathrm{~N}$ & $0.422 \mathrm{~N}$ & $0.422 \mathrm{~N}$ & $0.422 \mathrm{~N}$ & $0.422 \mathrm{~N}$ & $0.422 \mathrm{~N}$ & $0.421 \mathrm{~N}$ & $0.421 \mathrm{~N}$ & $0.420 \mathrm{~N}$ & $0.420 \mathrm{~N}$ & $0.419 \mathrm{~N}$ & $0.003 \mathrm{~N}$ & 3.62 & $\begin{array}{r}2.74 \\
\times 10^{\circ}\end{array}$ \\
\hline$F$ & $\begin{array}{l}\text { Rain } \\
\text { water }\end{array}$ & $0.413 \mathrm{~N}$ & $0.413 \mathrm{~N}$ & $0.413 \mathrm{~N}$ & $0.413 \mathrm{~N}$ & $0.413 \mathrm{~N}$ & $0.413 N$ & $0.413 \mathrm{~N}$ & $0.412 \mathrm{~N}$ & $0.412 \mathrm{~N}$ & $0.411 \mathrm{~N}$ & $0.411 \mathrm{~N}$ & $0.410 \mathrm{~N}$ & $0.409 \mathrm{~N}$ & $0.004 \mathrm{~N}$ & 3.62 & $\begin{array}{l}3.73 \\
\times 10^{4} \\
\end{array}$ \\
\hline 6 & $\begin{array}{l}\text { Acidic } \\
\text { water }\end{array}$ & $0.427 \mathrm{~N}$ & $0.427 \mathrm{~N}$ & $0.427 \mathrm{~N}$ & $0.427 \mathrm{~N}$ & $0.426 \mathrm{~N}$ & $0.426 \mathrm{~K}$ & $0.425 \mathrm{~N}$ & $0.425 \mathrm{~N}$ & $0.426 \mathrm{~N}$ & $0.425 \mathrm{~N}$ & $0.425 \mathrm{~N}$ & $0.422 \mathrm{~N}$ & $0.421 \mathrm{~N}$ & $0.006 \mathrm{~N}$ & 3.62 & $\begin{array}{l}5.59 \\
\times 10^{\circ} \\
\end{array}$ \\
\hline $\mathrm{H}$ & $\begin{array}{l}\text { Salty } \\
\text { water }\end{array}$ & $0.416 \mathrm{~N}$ & $0.416 \mathrm{~N}$ & $0.616 \mathrm{~N}$ & $0.419 \mathrm{X}$ & $0.615 \mathrm{X}$ & $0.610 \mathrm{x}$ & Q.eteV & $0.613 \mathrm{~N}$ & Q.2513N & $0.612 \mathrm{~V}$ & $0.412 \mathrm{~N}$ & $0.611 \mathrm{~N}$ & $0.411 \mathrm{~N}$ & $0.005 \mathrm{~N}$ & 3.62 & $\begin{array}{r}4.66 \\
\times 10^{4} \\
\end{array}$ \\
\hline
\end{tabular}

\subsection{Result Of Hardness Test}

The results of hardness test on all specimens can be shown in table 2. Specimen

A-D were tested on the body and the welded joint, while specimen E-H were tested only on the body.

Table 2 Brinnel Hardness Test Results

\begin{tabular}{|c|c|c|c|c|c|c|c|c|c|}
\hline \multirow{3}{*}{$\begin{array}{l}\text { specimen } \\
\text { A }\end{array}$} & \multirow{3}{*}{$\begin{array}{l}\text { medium } \\
\text { Air }\end{array}$} & \multirow{2}{*}{\multicolumn{4}{|c|}{$1^{\text {st }} \quad 2^{\text {BOD }}$}} & \multirow{2}{*}{\multicolumn{2}{|c|}{$1^{\text {st }}$}} & \multicolumn{2}{|c|}{ WELD } \\
\hline & & & & & & & & & mean \\
\hline & & 128 & 129 & 130 & 129 & 135 & 138 & 140 & 137.7 \\
\hline$B$ & Rain water & 115 & 117 & 118 & 120 & 120 & 125 & 122 & 122.3 \\
\hline C & Acidic water $\mathrm{h}_{2} \mathrm{SO4}$ & 93 & 94 & 99 & 95.3 & 92 & 95 & 94 & 93.7 \\
\hline $\mathrm{D}$ & $\begin{array}{l}\text { Salty water } \\
\mathrm{H}_{2} \mathrm{SO} 4\end{array}$ & 94 & 93 & 97 & 94.7 & 98 & 92 & 93 & 94.3 \\
\hline & Air & 110 & 107 & 105 & 107.3 & NA & NA & NA & NA \\
\hline $\mathrm{F}$ & Rain water & 113 & 114 & 112 & 113 & NA & NA & NA & NA \\
\hline G & Acidic water $\mathrm{h}_{2} \mathrm{SO}$ & 93 & 90 & 92 & 91.7 & NA & NA & NA & NA \\
\hline $\mathrm{H}$ & Salty water (nacl) & 135 & 133 & 130 & 132.7 & NA & NA & NA & NA \\
\hline
\end{tabular}


4.2 Results of Toughness Test

The specimens labeled E-H were subjected impact toughness tests and the result is shown in table 3.

Table 4.3 impact toughness test Results

\begin{tabular}{|l|l|l|}
\hline SPECIMEN E & DEDIUM & RESULTS \\
\hline $\mathrm{E}$ & Air & $187 \mathrm{~J}$ \\
\hline $\mathrm{F}$ & Rain water & $120 \mathrm{~J}$ \\
\hline $\mathrm{G}$ & Acidic water $\mathrm{H}_{2} \mathrm{SO}_{4}$ & $1.95 \mathrm{~J}$ \\
\hline $\mathrm{H}$ & Salty water $(\mathrm{NaCl})$ & $130 \mathrm{~J}$ \\
& & \\
\hline
\end{tabular}

4.3 Analysis of Hardness Test on Body and Welds of Specimens A-D using Analysis of Variance (ANOVA)

The analysis of variance (ANOVA) was applied on specimens A-D since hardness tests were carried out on the body and weld.

Table 4: Anova Table

\begin{tabular}{|c|c|c|c|}
\hline Welding Test & Body & Weld & \\
\hline \multirow[t]{4}{*}{ A } & 128 & 135 & $X 1.1=263$ \\
\hline & 129 & 138 & $X 1.2=267$ \\
\hline & 130 & 140 & $X 1.2=270$ \\
\hline & $X 11 .=387$ & $X 12 .=413$ & $X 1.4=800$ \\
\hline \multirow[t]{5}{*}{$B$} & 115 & 120 & $X 2.1=235$ \\
\hline & 117 & 122 & $X 2.2=239$ \\
\hline & 118 & 125 & $X 2.3=243$ \\
\hline & $X 21 .=350$ & $X 22 .=367$ & $X 2 .=717$ \\
\hline & 93 & 92 & $X 3.1=185$ \\
\hline \multirow[t]{3}{*}{$\mathrm{C}$} & . & 95 & $X 3.2=189$ \\
\hline & & 94 & $x 3.3=193$ \\
\hline & $X 31 .=286$ & $X 32 .=281$ & $X 3 .=567$ \\
\hline \multirow[t]{5}{*}{$D$} & 94 & 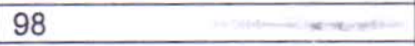 & $X 4.1=193$ \\
\hline & 93 & 92 & $X 4.2=185$ \\
\hline & 97 & 93 & $X 4.3=190$ \\
\hline & $X 41 .=284$ & $X 42 .=283$ & $X 4 .=567$ \\
\hline & $X .1 .=1307$ & $X .2 .=1344$ & $X .3 .=2651$ \\
\hline
\end{tabular}

\subsection{Research Hypothesis:}

$\mathrm{H}_{0}$ :There is no significant difference between the hardness of the body and hardness of the weld of the four treatments

$H_{0}: \alpha_{J}=0$

$H_{1}: \alpha_{J} \neq 0$

Taking Level Of Significance $=0.05$

Total Sum of Square SST $\sum_{1} \sum_{j \sum k} X_{1}^{2}-C$ 
Where $\quad \mathrm{C}=\frac{x^{2} \ldots}{[J K}$

$=\frac{2651^{2}}{4 \times 2 \times 3}$

$292825 \quad .05$

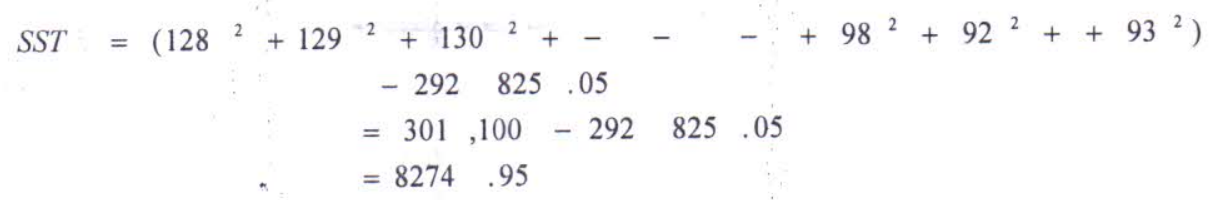

treatment sum of square

$S S A=\frac{\sum_{j} x^{2}}{i k} \cdot j . \quad-C$

$=\frac{1307^{2}+1344^{2}}{4 \times 3}-292825.05$

$=\frac{3514585}{12}-292 \quad 825.05$

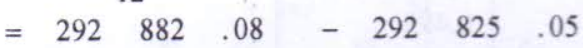

$=5703$

blocks sum of square

$S S B=\sum, \frac{x^{2} i \ldots}{J K}-C$

$=\frac{800^{2}+717^{2}+567^{2}}{2 \times 3}-292825.05$

$=\frac{179067}{.6}-292 \quad 825 \quad .055$

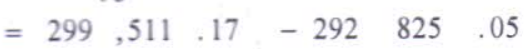

$=6696.12$

$A B=\Sigma, \Sigma, \frac{x^{2} i j . .}{J K}-\sum, \frac{x^{2} i . .}{J K}-\sum_{j} \frac{x^{2} \cdot j .}{I K}+C$

but

$\sum_{i} \sum_{j} \frac{x^{2}{ }_{i j .}}{K}$

$\frac{387^{2}+350^{2}+286^{2}+284^{2}+413^{2}+367^{2}+281^{2}+283^{2}}{3}$

$=299676.33-299511.17-292882.05+292825.05$

$=108.13$ 


\section{Table 5: Anova Result Table}

\begin{tabular}{|c|c|c|c|c|c|}
\hline $\begin{array}{l}\text { source of } \\
\text { variation }\end{array}$ & Df & Ss & Ms & $F_{\text {-ratio }}$ & $F_{\text {-table }} \alpha=0.05$ \\
\hline $\begin{array}{l}\text { Treatment(A } \\
\text { ) }\end{array}$ & $\begin{array}{l}J-1 \\
2-1=1\end{array}$ & SSA 57.03 & $\begin{array}{c}M S A=\frac{S S A}{J-1} \\
=\frac{57.03}{1} \\
=57.03\end{array}$ & $\begin{array}{l}\frac{M S A}{M S E} \\
\frac{57.03}{88.98}=0.6409\end{array}$ & $\begin{array}{l}F_{j-1,}(k-1), \alpha \\
v_{1}=1 \\
v_{2}=2 \\
1995\end{array}$ \\
\hline Block B & $\begin{array}{l}I-1 \\
4-1=3\end{array}$ & $S S B=6686.12$ & $\begin{array}{l}M S B \\
=\frac{S S B}{I-1}=\frac{6686.12}{3} \\
=2228.71\end{array}$ & $\begin{array}{l}\frac{M S B}{M S E} \\
\frac{2228.71}{88.98} \\
=25.05\end{array}$ & $\begin{array}{l}F_{r-1, i j}(k-1) \\
\alpha v_{123} v_{2}=16 \\
0.495\end{array}$ \\
\hline $\begin{array}{l}\text { Interaction } \\
\text { Conjunction } \\
\text { of factors } \\
\text { A \&B) }\end{array}$ & $\begin{array}{l}(1-1) \\
(J-1) \\
3 \times 1 \\
=3\end{array}$ & $\begin{array}{l}\text { SSAB } \\
108.13\end{array}$ & $\begin{array}{l}\text { MSAB } \\
=\frac{S S A B}{(J-1)(J-!)}=36.04 \\
108.13\end{array}$ & $\begin{array}{l}\frac{M S A B}{M S E} \\
\frac{36.04}{88.98} \\
=0.405\end{array}$ & $\begin{array}{l}F(1-1)(J-1), \\
13(k-1) \\
v_{1}=3 \\
v_{2}=16 \\
0.495\end{array}$ \\
\hline Error & $\begin{array}{l}I J(K-I) \\
4 X 2(3-1) \\
16\end{array}$ & $\begin{array}{l}\text { SSE } \\
1423.67\end{array}$ & $\begin{array}{l}M S \\
=\frac{S S E}{I J(K-1)} \\
\begin{array}{l}\frac{1423.67}{16} \\
=88.98\end{array}\end{array}$ & & \\
\hline
\end{tabular}

SSE $=\sum_{i}, \sum_{K} x_{i j}^{2} k-\sum_{i} \sum_{j} \frac{x_{i j}^{2}}{K}$

$301,100-299676.33$

$=1423.67$

\subsection{Interpretation of Result}

Fcal $0.6409<\mathrm{F}$ tab 199.5 Accept the null hypothesis meaning there is no significance difference between the hardness of the body and the weld area.

$\mathrm{F}$ cal $0.495<\mathrm{F}$ tab 0.495 meaning there is interaction between the treatment and the material.

$F_{c a l} 25.05>f_{t a b} 0.495$, Meaning there is no significant difference between the hardness of the weld and the body of the material.

\subsection{Comparison of Hardness Tests And Impact Tests}

Specimens $E-H$ were subjected to both hardness tests and impact tests. The mean value of the hardness teat results are being compared to the impact test results. It should be noted that values with decimals are rounded up to the nearest whole number

Table 6 Comparison of hardness test and impact test results.

\begin{tabular}{|l|l|l|l|}
\hline Specimen & Medium & Hardness results & Toughness Results \\
\hline E & Air & $107 \mathrm{BHN}$ & $187 \mathrm{~J}$ \\
\hline $\mathrm{F}$ & Rain water & $113 \mathrm{BHN}$ & $120 \mathrm{~J}$ \\
\hline $\mathrm{G}$ & Acidic water & $92 \mathrm{BHN}$ & $195 \mathrm{~J}$ \\
\hline $\mathrm{H}$ & Salty water & $133 \mathrm{BHN}$ & $130 \mathrm{~J}$ \\
\hline
\end{tabular}




\subsection{Analysis Of Hardness Test and Impact Test Results}

\subsection{Using Chi-Square Test}

The chi-square tests involved comparing observed or measured value to the expected value Hypothesis $\mathrm{H}_{0}$ : The hardness of a material significantly impact on the toughness of the material.

Table 7: Observed values of hardness toughness results

\begin{tabular}{|l|l|l|l|l|l|}
\hline Tests & I & II & III & IV & Total \\
\hline Hardness (BHN) & 107 & 113 & 92 & 133 & 445 \\
\hline Toughness $(\mathrm{J})$ & 187 & 120 & 195 & 130 & 632 \\
\hline Total & 294 & 223 & 287 & 263 & 1077 \\
\hline
\end{tabular}

Table 8: Expected values of hardness and toughness results

Table 8: Expected values of hardness and toughness results
\begin{tabular}{|l|l|l|l|l|}
\hline Test & I & II & III & IV \\
\hline Hardness (BHN) & 121.5 & 96.3 & 118.6 & 108.7 \\
\hline Toughness $(\mathrm{J})$ & 172.5 & 136.7 & 168.4 & 154.3 \\
\hline
\end{tabular}

Using the formula

Chi-square $X^{2}=\sum_{j=i}^{k} \frac{(o j-e j)^{2}}{e j}$

$=\frac{\left(0_{1}-e_{1}\right)^{2}}{e_{1}}+\frac{\left(0_{2}-e_{2}\right)^{2}}{e_{2}}+--+\frac{\left(0_{k}-e_{k}\right)^{2}}{e_{k}}$

$=\frac{(107-121.5)^{2}}{121.5}+\frac{(187-172.5)^{2}}{172.5}+\frac{(113-96.3)^{2}}{96.3}+\frac{(120-136.7)^{2}}{136.7}+\frac{(92-118.6)^{2}}{118.6}$

$\frac{(195-168.4)^{2}}{168.4}+\frac{(133-108.7)^{2}}{108.7}+\frac{(130-154.3)^{2}}{154.3}$

$=1.73+1.22+2.90+2.04+5.96+4.20+5.43+3.83$

Calculated $x^{2}=27.3$

Degree of freedom $v=(h-1)(k-1)$

$$
\begin{aligned}
& =(2-1)(4-1) \\
& =1 \times 3 \\
\therefore \text { df } & 3
\end{aligned}
$$

Level of significance $=0.005$

$$
x^{2}=12.8
$$

Decision: There is disagreement between the observed and expected values

\section{DISCUSSION OF RESULTS}

Generally, the results obtained from the experiment and analysis of data buttress the fact that the properties of the specimens were affected by the various treatments they were subjected.

\section{CONCLUSION}

Conclusively, corrosive environments affect same mechanical properties of mild steel like weight, hardness and toughness. The rate of corrosion depends on the environments in which machines and equipment that are made of mild steel are kept. There is need to protect our machines and equipment from the effect of corrosion. 


\section{FINDINGS}

The following findings were made during the process of carrying out this research:

1. All metals, especially mild steel corrode when exposed to corrosive environments

2. The rate of corrosion for acidic and basic environments are high

3. The hardness of mild steel is increased in a basic environment.

4. The toughness of mild steel is increased in an acidic environment

5. All environments including air are corrosive to some level.

\section{RECOMMENDATION}

The following recommendations are made so that our expensive and precision equipment and machines can be preserved or protected from corrosion:

1. All bodies and internal parts made of mild steel should be protected from corrosion using the various protective methods.

2. Sensitive equipment like parts of aircraft that are made of steel should be manufactured with corrosion resistant steels.

3. All equipment and machines in our workshops should be checked for corrosion periodically so that appropriate measures can be taken to protect them on time

4. Studies on corrosion should be intensified so that new modern methods of protection and prevention can be discovered

5. Workers in charge of purchasing should inspect items for corrosion and request those that are not protected should be rejected.

\section{REFERENCES}

1. Borode J.O. and Okpala A.N. (1999): Effects of Carbon Content and Inhibitors on Corrosion of Steels in $3 \%$ $\mathrm{NaCl}$ solution. Nigerian Corrosion Journal (NCJ) Vol.2.

2. Callister W.D. Jr. (2011): "Callister's Materials Science and Engineering" in Balasubramaniam R (Adopted) New Delhi: Sanjeer Offset Printers.

3. Chakravarthy M.P and Mohana K.N (2013): inhibition Behavior of some Isonicotinic Acid Hydrazides on the Corrosion of Mild Steel in Hydrochloric Acid Solution. International Journal on Corrosion. An Open Access Journal. Hindawl Publishing Corporation.

4. Emeghara A. I. and Iroanya A.C (1999): Environmental Protection in the Oil and Gas Industries through a Comprehensive Programme of Catholic Protection System. A Case study of Land Based Flow Lines in SPDCProceedings of $2^{\text {nd }}$ International Corrosion Conferences; $17^{\text {th }}-20^{\text {th }}$ November, 1999.

5. Idenyi N.E, Neife S.I and Uzor A. (2004): The Corrosion Behaviour of Recrystallized Mild Steel in various Tetraoxosulphate (vi) Acid $\left(\mathrm{H}_{2} \mathrm{SO}_{4}\right)$ Concentrations. Journal of Corrosion Science and Technology. Vol 1.1 Special Edition.

6. Ihom P.O (2004): Adoption of Good Professional ethics in Material Selection for "Corrosion Control in Engineering and Processing Concerns. Journal of Corrosion Science and Technology. Vol. 1.1 special Edition Nwoko V.O and Umoru L.E (2008): Corrosion of mild steel in some Environments. Nigerian Corrosion Journal (NCJ) Vol 1, No 1.

7. Okonji P.O, Okonji R.E and Ikpesini S. (2008): Steel Development: a Strategy for Successfully Poverty Alleviation programme in Nigeria. Journal of Engineering Technology and Economic Dev. Vol 1, No 1.

8. Renato A.A. Rodrigo U.I, Luis G.M and Isolda C. (2004), Characterization of Corrosion Products on Carbon Steel Exposed to National Weathering and Accelerated Corrosion Tests. International Journal on Corrosion. An open Access Journal. Hindawl Publishing Corporation 